\title{
Finite Element Analysis of Resin Mineral Composites Lathe Bed
}

\author{
Wenqiang Wang ${ }^{\mathrm{a}}$, Jianhua Zhang ${ }^{\mathrm{b}_{*}}$, Jicai Yin $^{\mathrm{c}}$ and Yi Zhang ${ }^{\mathrm{d}}$ \\ Key Laboratory of High Efficiency and Clean Mechanical Manufacture, Ministry of Education of \\ China, School of Mechanical Engineering, Shandong University, Jinan, China, 250061; \\ awwqsdu@outlook.com, bjhzhang@sdu.edu.cn, ' szyinjicai2008@163.com, ${ }^{\mathrm{d}}$ zhangyi.sdu@163.com
}

Keywords: Resin Mineral Composites (RMC), Finite Element Analysis, Lathe Bed.

\begin{abstract}
To study the static and dynamic performances of lathe bed made of resin mineral composite, a series of finite element analysis by ANSYS Workbench for lathe beds made of cast iron and resin mineral composite are conducted respectively in this article. It is proved by the results acquired from the static and modal analyses that the lathe bed made of resin mineral composite is better in both static and dynamic performances. The analyses results also give guidance to the design of resin mineral composite lathe bed.
\end{abstract}

\section{Introduction}

With the development of high speed and ultra-precision machining technology, using materials with high strength and damping properties have become a new trend for machine tool beds [1]. Traditional materials like cast iron are widely used as machine tools bed, but they can hardly meet the need of dynamic properties, heat stability and corrosion resistance.

Resin mineral composite (RMC) is a new kind of material which has been more and more used as machine tool bed materials, especially in the field of high speed and ultra-precision machining [2]. It is manufactured by mixing a monomer or resin with aggregate and polymerizing which has prominent static and dynamic performances.

\section{Modeling}

The models established in Solid Works are imported into ANSYS Workbench, and some complicated factors originating from the heterogeneous property of RMC are minimized and several simplified assumptions are proposed for the simulation convenience, for example, all small holes and chamfers are ignored. The cast iron (HT300) bed and the RMC bed are shown in Fig.1, sharing the same overall dimensions of $1970 \mathrm{~mm} \times 1195 \mathrm{~mm} \times 1062 \mathrm{~mm}$.

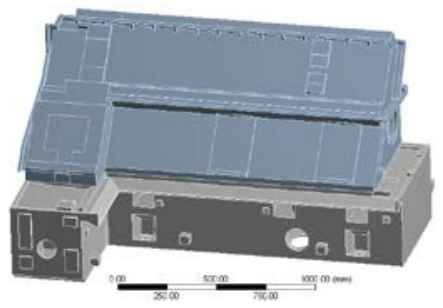

(a) The simplified model of HT300 lathe bed

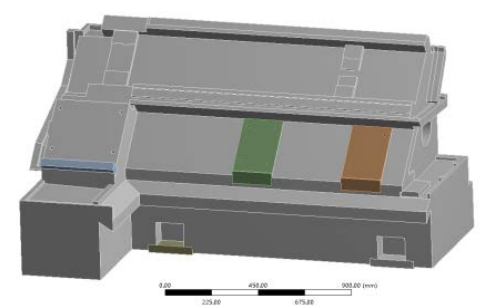

(b) The simplified model of RMC lathe bed

Fig.1 The simplified lathe bed model

Necessary input data such as the material properties including modulus of elasticity, poison ratio and density are applied. The material data of HT300 and RMC is shown in Table 1. 
Table 1 Material properties

\begin{tabular}{ccc}
\hline Material & HT300 & RMC \\
\hline Density (kg/m3) & 7300 & 2600 \\
Modulus of Elasticity(GPa) & 130 & 42 \\
Poison Ratio & 0.25 & 0.27 \\
\hline
\end{tabular}

The two lathe beds are both meshed through the mesh tool by intelligent grid with the same method and dimensions. Fixed support is imposed on the bottom of the anchors.

\section{Static Analysis}

The same loads are applied on the according faces of the two beds as shown in Fig.2. The total deformations and the equivalent stress are calculated. And the simulation results of lathe beds made of the two kinds of materials are shown in Fig 3.

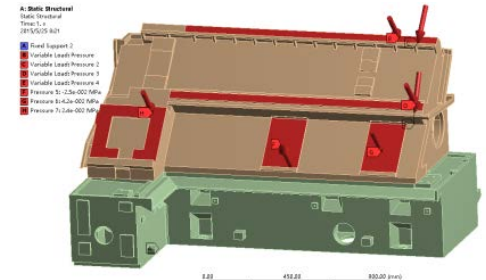

(a) Loads on HT300 lathe bed



(b) Loads on RMC lathe bed

Fig.2 Loads applied on the two beds

The static analysis results indicate that the total deformation of RMC lathe bed is similar to the bed of HT300, but the value is less than the one of TH300 bed. The maximum deformation of TH300 lathe bed is $15.2 \mathrm{um}$, occurring on the middle part of the top guide way. The total deformation of $\mathrm{RMC}$ bed is 7.2um. It is the same as the equivalent stress. The maximum equivalent stress of HT300 and RMC bed are respectively 3.8MPa and 2.8MPa. The results are shown in Table 2.

Table 2 Summery of static analysis

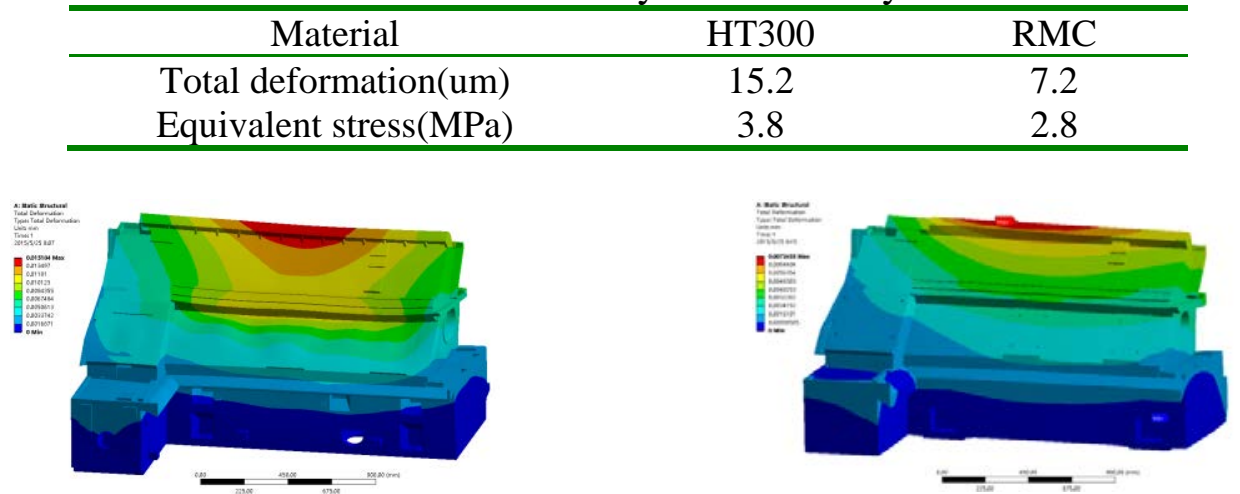

(a) Total deformation of HT300 lathe bed

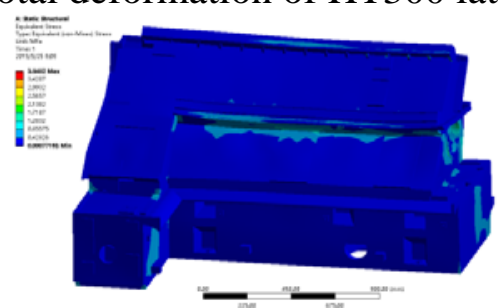

(c) Equivalent stress of HT300 lathe bed (b) Total deformation of RMC lathe bed

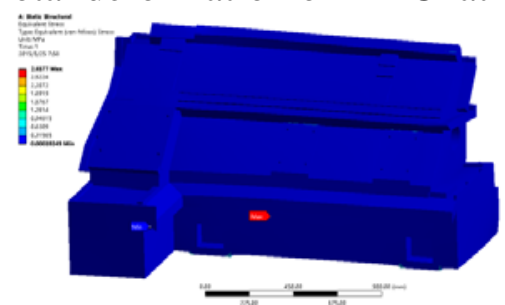

(d) Equivalent stress of RMC lathe bed

Fig.3 Static analysis results of the two beds 


\section{Modal Analysis}

Although the lathe beds have countless degrees of freedom and innumerable modals because of the distribution of mass and elasticity, the vibration frequency of machine tools is low [3]. When the excitation frequency is close to the natural frequency of lathe beds, it will leads to resonance which will cause great damage to the machining tool and the work piece. So that the first six orders frequencies should be simulated [4]. The modes of vibration plot are as shown in Fig.4.

Modal analysis results indicated that the maximum relative displacement of first six orders of RMC bed are less than HT300 lathe bed significantly. The first four orders natural frequencies of the two machine tool beds through finite element analysis are shown in Table3.

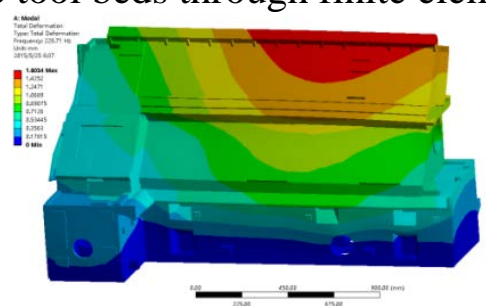

(a) The 1st order vibration mode of HT300 lathe bed

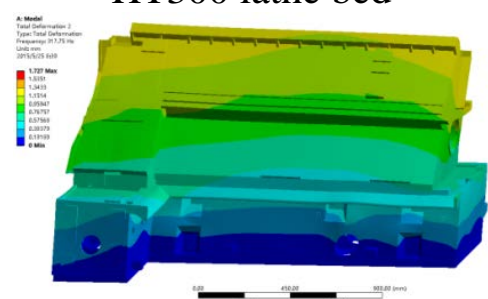

(c) The 2nd order vibration mode of HT300 lathe bed

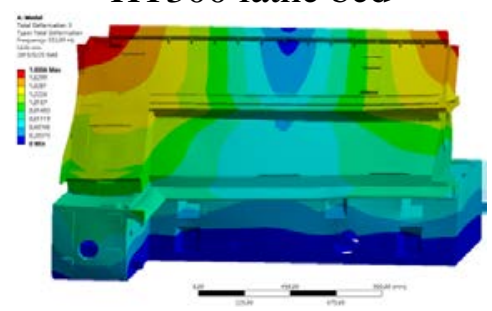

(e) The 3rd order vibration mode of HT300 lathe bed

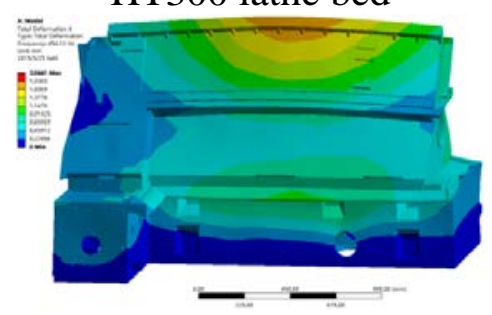

(e) The 4th order vibration mode of HT300 lathe bed

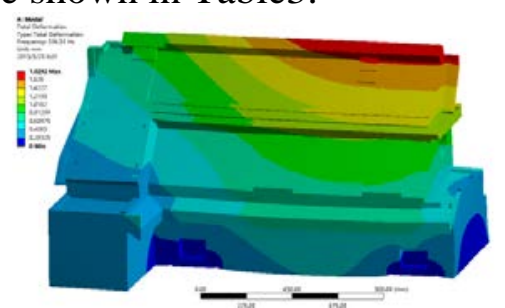

(b) The 1st order vibration mode of RMC lathe bed

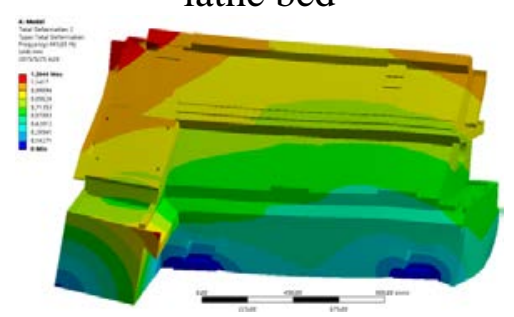

(d) The 2nd order vibration mode of RMC lathe bed

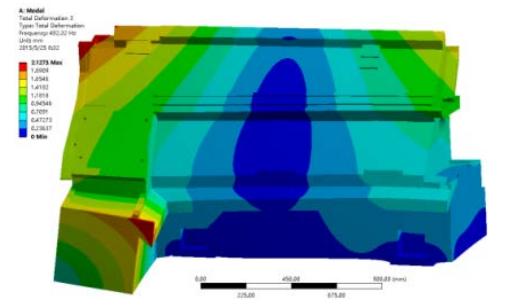

(f) The 3rd order vibration mode of RMC

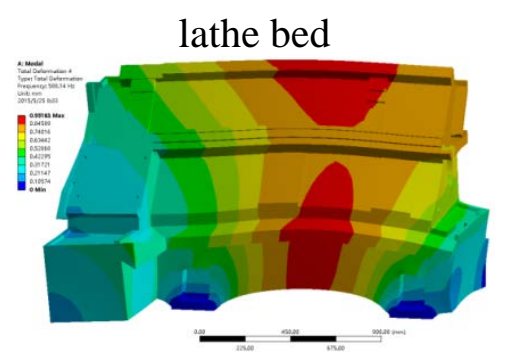

(e) The 4th order vibration mode of RMC lathe bed

Fig. 4 The preceding four orders vibration modes

Table 3 Summery of modal analysis

\begin{tabular}{cccc}
\hline Order & HT300(Hz) & RMC(Hz) & Improvement (\%) \\
\hline 1 & 228 & 336 & 47 \\
2 & 317 & 443 & 40 \\
3 & 352 & 482 & 37 \\
4 & 454 & 588 & 30 \\
5 & 497 & 634 & 28 \\
6 & 528 & 724 & 37 \\
\hline
\end{tabular}


As shown in table 3, the preceding six orders natural frequencies of RMC bed are higher than those of HT300 lathe bed, increased by $47 \%, 40 \%, 37 \%, 30 \%$, $28 \%$ and 37\%, respectively. The possibility of resonating during machining process will be greatly reduced.

\section{Optimization}

The results of static and modal analysis indicate that the guide ways are the weaknesses of the lathe bed, therefore certain structural steel needs to be embedded in the guide ways. And it's also necessary to thicken the back of the guide way backward by $50 \mathrm{~mm}$ to enhance the bed performance partially.

\section{Summary}

Conclusion can be draw from the analyses above that the resin mineral composite has better static and dynamic performances than cast iron. It is more suitable to be used as machining tool bed material. And the analysis results also work as kind of guidance of the lathe bed design.

\section{Acknowledgements}

The work of this paper is supported by the National Science and Technology Major Project of China (Grant No.2012ZX04010032).

\section{References}

[1] Berthelot J M, Assarar M, Sefrani Y, et al. Damping analysis of composite materials and structures[J]. Composite Structures, 2008, 85(3): 189-204.

[2] Kim H S, Park K Y, Lee D G. A study on the epoxy resin concrete for the ultra-precision machine tool bed[J]. Journal of materials processing technology, 1995, 48(1): 649-655.

[3] J. H. Zhang and P. Zeng: Finite element analysis of $400 \mathrm{MN}$ aviation die forging hydraulic press frame [J]. Forging\&Stamping Technology, Vol. 34 (2009) p.93-96.

[4] H. L. Hou, Z. H. Qiu and Y. Q. Zhao : Static \& dynamic analysis for beam of high-speed cutting machine tool.[J]. Machinery Design \& Manufacture, Vol. 5 (2005) p. 38-39. 